\title{
Stress analysis on large-diameter buried gas pipelines under catastrophic landslides
}

\author{
Sheng-Zhu Zhang ${ }^{1}$ Song-Yang $\mathrm{Li}^{2} \cdot$ Si-Ning Chen ${ }^{1} \cdot$ Zong-Zhi $\mathrm{Wu}^{3} \cdot$ \\ Ru-Jun Wang ${ }^{1} \cdot$ Ying-Quan Duo ${ }^{1}$
}

Handling editor: Jian Shuai

Received: 12 December 2016/Published online: 8 July 2017

(c) The Author(s) 2017. This article is an open access publication

\begin{abstract}
This paper presents a method for analysis of stress and strain of gas pipelines under the effect of horizontal catastrophic landslides. A soil spring model was used to analyze the nonlinear characteristics concerning the mutual effects between the pipeline and the soil. The Ramberg-Osgood model was used to describe the constitutive relations of pipeline materials. This paper also constructed a finite element analysis model using ABAQUS finite element software and studied the distribution of the maximum stress and strain of the pipeline and the axial stress and strain along the pipeline by referencing some typical accident cases. The calculation results indicated that the maximum stress and strain increased gradually with the displacement of landslide. The limit values of pipeline axial stress strain appeared at the junction of the landslide area and non-landslide area. The stress failure criterion was relatively more conservative than the strain failure criterion. The research results of this paper may be used as a technical reference concerning the design and safety management of large-diameter gas pipelines under the effects of catastrophic landslides.
\end{abstract}

Keywords Buried gas pipeline - Catastrophic landslide . Finite element analysis $\cdot$ Stress $\cdot$ Strain

Sheng-Zhu Zhang

zhangshengzh5168@163.com

1 China Academy of Safety Science and Technology, Beijing 100012, China

2 College of Mechanical and Transportation Engineering, China University of Petroleum, Beijing 102249, China

3 State Administration of Work Safety, Beijing 100713, China

Edited by Yan-Hua Sun

\section{Introduction}

Landslides are a common geological disaster frequently occurring in mountainous areas of the southwest provinces, the Loess Plateau in the northwest, as well as mountainous and hilly areas of the mid-south and southeast provinces in China. Newly built pipelines have to pass through small landslide areas, and if it is not possible to be avoided, then during the operation period of pipelines, soil piling, excavation and other third-party activities around the pipeline may damage the stability of rock and earth mass, resulting in a landslide (Yu 1989; Challamel and Debuhan 2003). The large-diameter gas pipeline connects the gas source to the consumer over a long route, and it often crosses over areas with complex conditions (Hucka et al. 1986; Hall et al. 2003). Therefore, we often suffered from landslide disasters. Before the year 2000, more than ten pipeline accidents were caused by landslides and other geological disasters occurred to the natural gas pipeline in Sichuan Province (Wang 2014). As reported by European Gas Pipeline Incident Data Group, the accidents caused by geological disasters accounted for $13 \%$ of the total amount of gas pipeline accidents which happened in Europe from 2004 to 2013, of which landslides accounted for $85.2 \%$ of all geological disasters, forming the leading geological disaster type (EGIG 2015). Especially under the effects of catastrophic landslides, the pipeline and even the surrounding people will be severely influenced (Honegger et al. 2010; Liu et al. 2010; Zheng et al. 2012). With the continuous construction of large-diameter gas pipelines, an increasing number of geological disasters such as landslides caused by various factors happen along the pipeline, which brings a great challenge to the safe operation of pipelines (Wang et al. 2008). Therefore, it is necessary to make a stress analysis on large-diameter buried gas pipelines under the effects of catastrophic landslides. 
For the stress condition of pipelines under the effect of landslides, Rajani et al. (1995) studied the stress response of pipelines under the effect of a horizontal landslide using an analytical method. O'Rourke et al. (1995) studied the stress features of deviated pipeline landslide areas using the Ramberg-Osgood power hardening formula. Deng et al. (1998) studied the calculation methods of internal force and deformation under other soil mass loads, during horizontal landslides. Shuai et al. (2008) studied the failure characteristics of pipelines under the effect of landslides. Zhang et al. (2010) investigated the interaction of landslides and pipelines. Hao et al. (2012) studied the calculation of horizontal thrust imposed on pipelines by landslides. Lin et al. (2011) established a soil quality landslide model under fully buried conditions and carried out a test on the pipeline stresses under the effects of a landslide. However, studies of the stress condition of buried pipelines under the effects of catastrophic landslides are rarely made. Aiming at the working conditions of buried gas pipelines with large diameters, the authors created a soil spring analysis model for the pipeline under the effects of catastrophic landslides using ABAQUS finite component analysis software, as well as making a finite element analysis on the pipeline stresses and deformation, which can be used as a reference for safety design and operations in landslide areas.

\section{The interactive process of landslide mass and pipeline under the effects of catastrophic landslides}

Pipelines may pass through landslide masses through two methods, namely horizontal pass-through and vertical passthrough. This paper only analyzes the stress condition of pipelines under horizontal pass-through. When the pipeline passes through the landslide mass horizontally, the slide direction of the landslide mass is at right angles to the pipeline axis (Ma et al. 2006; Han et al. 2012). The evenly distributed load endured by the pipeline is in the horizontal and vertical directions. Under the effect of the landslide mass, the buried pipeline may displace for a certain degree. The accident process of the buried pipeline before and after a landslide is shown in Fig. 1. This finite component analysis considered the buried pipeline and the surrounding soil mass as a system.

\section{Load calculation of pipelines across landslide mass}

Considering the material nonlinearity and geometric nonlinearity of the buried pipeline and soil mass, a nonlinear soil spring element was used to simulate the interaction of soil and pipes (Wang and Yeh 1985; Zheng et al. 2015). The soil spring model disperses the effects of soil on the pipeline to be springs with different stiffness in the axial, vertical and horizontal directions (Kennedy et al. 1977; Iimura 2004; Yan et al. 2009). The axial soil spring parameters are decided by the backfill in the pipe ditch, while the horizontal and vertical soil spring is determined by the nature of soil mass around the pipeline burying site. The soil joint was set up connected to each joint outside of all the nodes on the pipeline, and the JOINTC unit was used to connect the pipeline to the soil joint to simulate the effects of a soil spring. A JOINTC unit can describe the interactive force generated by the change of relative displacement between two joints. The mechanical properties of the soil spring were described by ultimate soil resistance and yield displacement. $T_{\mathrm{u}}, Q_{\mathrm{u}}, Q_{\mathrm{d}}$ and $P_{\mathrm{u}}$ represent the ultimate resistance in the three directions, and $\Delta t, \Delta q_{\mathrm{d}}, \Delta q_{\mathrm{u}}$ and $\Delta p$ represent the yield displacement in the three directions, respectively, as shown in Fig. 2. The specific value can be calculated based on the Guideline for the Design of Buried Steel Pipeline published by American Lifelines Alliance (ALA 2001).

When the size of the structure in the direction of thickness is less than the sizes in the other two directions, and when the stress in the direction of thickness can be neglected, the shell element can be used for stimulation. Concerning a thin-walled pipeline with a large diameter, when the wall thickness is less than $1 / 10$ of the overall structure size, the pipeline is dispersed as several rectangular shell elements to accurately describe the deformation of the pipeline under the effects of force or displacement loads, and the distribution of stress strain (Klar and Marshall 2008; Liu et al. 2014; Zhao and Zhao 2014). This paper established a long-distance pipeline model with four joints and reduced integration shell element S4R. The S4R element has six degrees of freedom on each joint, including 3 transitional degrees of freedom and 3 rotational degrees of freedom.

Considering the nonlinear characteristics of pipes, the Ramberg-Osgood ( $\mathrm{R}-\mathrm{O}$ ) model was used to describe the stress-strain relationship of pipes, as shown in Eq. (1):

$\varepsilon=\frac{\sigma_{\mathrm{s}}}{E}\left[\frac{\sigma}{\sigma_{\mathrm{s}}}+\frac{n}{1+r}\left(\frac{\sigma}{\sigma_{\mathrm{s}}}\right)^{r}\right]$

where $E$ is the initial elastic modulus of pipe, $\mathrm{Pa} ; \varepsilon$ is strain; $\sigma$ is stress, $\mathrm{Pa} ; \sigma_{\mathrm{s}}$ is the yield stress of pipe, $\mathrm{Pa} ; r$ and $n$ are $\mathrm{R}-\mathrm{O}$ model parameters.

During the calculation, fixed constraints were imposed on circular joints on both ends of the pipeline to simulate the effects of infinite extension of the pipeline on the studied pipe section. The fixed constraints were imposed on the area outside the landslide area, in order to limit its movement and simulate the constraints and supporting 
(a)

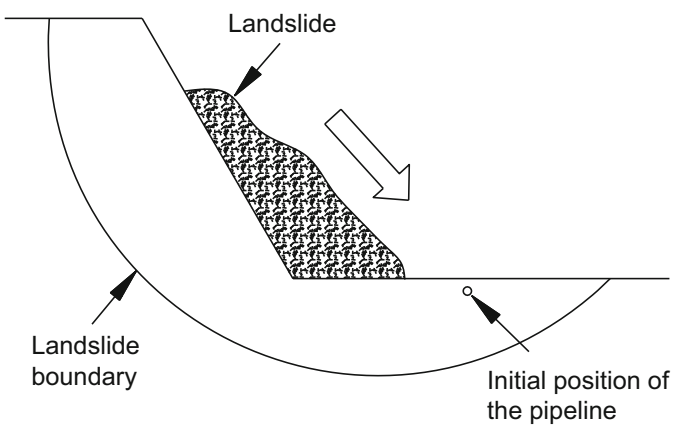

(b)

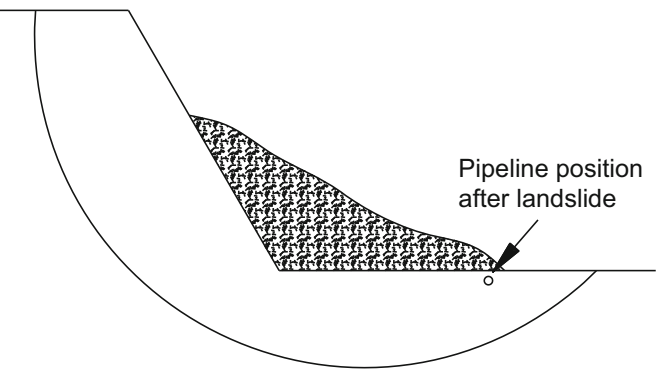

Fig. 1 Accident process of the buried pipeline before and after a landslide

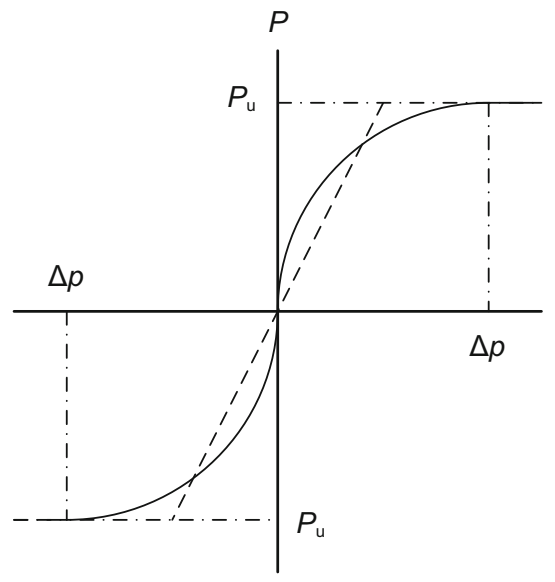

Transverse horizontal

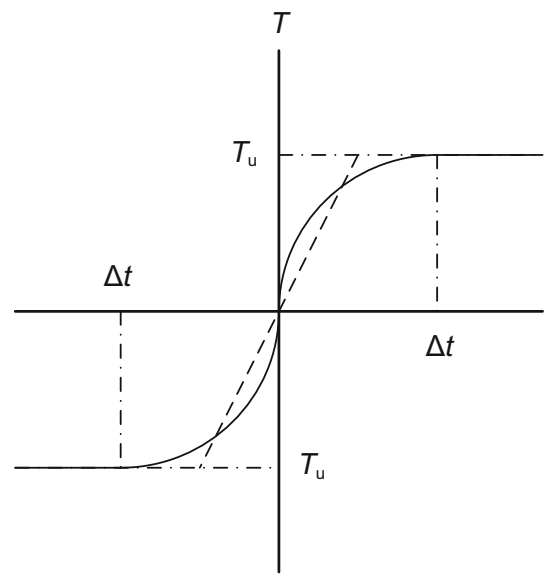

Axial

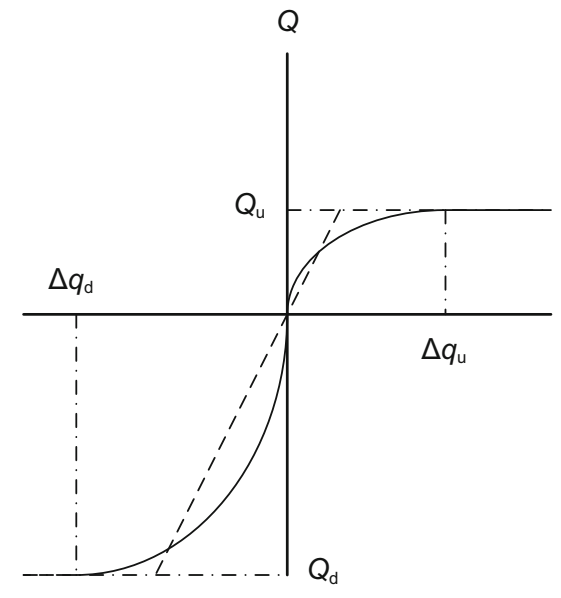

Transverse vertical

Fig. 2 Schematic diagram of soil spring effect

effects on the soil mass around the pipeline (Zhang and Huang 2012). When loading the load, the internal force is imposed on the entire management element, and then, a relative displacement is imposed based on the soil spring joint in the landslide area against the landslide direction, in order to simulate the effects of soil movement on the pipeline. Since the volume of landslide mass is larger than the pipeline, the integral movement of landslide is not influenced by the pipeline when the landslide is pushing and squeezing the pipeline. It is assumed that the movement speeds of the horizontal parts of the landslide are consistent, the displacement load of soil mass sliding downwards is evenly distributed, and the vertical friction of the soil mass against the pipeline is neglected.

\section{Stress analysis of a pipeline in the landslide mass in a landslide area}

\subsection{Model overview}

The corresponding value calculation model was established based on the design data of a large-diameter gas pipeline in a landslide area. The entire section of the model was laid out by burying it underground. To build in the pipeline model, the pipeline parameters were assigned with values shown in Table 1. The values of the soil spring parameters were calculated according to the site survey results of a catastrophic landslide accident, and the formula specified in the ALA Guideline for the Design of Buried Steel Pipeline, as shown in Table 2. The pipeline was made of $\mathrm{X} 70$ steel, and the R-O model parameters $r$ and $n$ were assigned with 16.6 and 5.5, respectively, as described in the literature (Liu and Sun 2005).

\subsection{Modeling}

To reduce the effect of fixed end boundary conditions on the calculation results, circular joints at the end of the shell element pipeline and six degrees of freedom of the soil joints were all constrained. As described in the literature (Liu 2008), when the length of the non-slide area was four times the length of the slide area, the requirements for calculation accuracy can be assured. In this case, while the length of the landslide area is $370 \mathrm{~m}$, the analysis length of the shell element model is $1850 \mathrm{~m}$. 
Table 1 Pipeline parameters

\begin{tabular}{|c|c|c|c|c|c|c|c|c|c|}
\hline Pipe & $\begin{array}{l}\text { Diameter, } \\
\mathrm{mm}\end{array}$ & $\begin{array}{l}\text { Wall } \\
\text { thickness, } \\
\mathrm{mm}\end{array}$ & $\begin{array}{l}\text { Elastic } \\
\text { modulus, } \\
\mathrm{GPa}\end{array}$ & $\begin{array}{l}\text { Poisson's } \\
\text { ratio }\end{array}$ & $\begin{array}{l}\text { Minimum } \\
\text { tensile } \\
\text { strength, } \mathrm{MPa}\end{array}$ & $\begin{array}{l}\text { Minimum } \\
\text { yield strength, } \\
\mathrm{MPa}\end{array}$ & $\begin{array}{l}\text { Density of } \\
\text { natural gas, } \\
\mathrm{kg} \mathrm{m}^{-3}\end{array}$ & $\begin{array}{l}\text { Transportation } \\
\text { temperature, } \\
{ }^{\circ} \mathrm{C}\end{array}$ & $\begin{array}{l}\text { Transportation } \\
\text { pressure, } \mathrm{MPa}\end{array}$ \\
\hline X70 & 1016 & 21 & 207 & 0.3 & 570 & 485 & 95 & 20 & 3.8 \\
\hline
\end{tabular}

Table 2 Soil spring parameters

\begin{tabular}{lllll}
\hline Parameters & Pipe axis direction & Horizontal direction & Vertical upward & Vertical downward \\
\hline Yield stress, $\mathrm{kN} \mathrm{m}^{-1}$ & 135 & 821 & 150 & 10,059 \\
Yield displacement, $\mathrm{m}$ & 0.008 & 0.0886 & 0.1708 & 0.2032 \\
\hline
\end{tabular}

The pipeline is divided into 24 elements in the circumferential direction by mesh generation against the model. To ensure the simulation accuracy of pipeline stress strain in the landslide area, it is necessary to densify the mesh near the landslide area, and to set the axial length of the three sections of pipeline elements (Sects. 2, 3, 4) at $0.25 \mathrm{~m}$, and the length of Sects. 1 and 5 at $1 \mathrm{~m}$, as shown in Fig. 3. Based on the results of the site survey and analyzing the influence of different values of landslide displacements, the displacement is imposed on the pipeline slide area. The vertical displacement is set at $0.2 \mathrm{~m}$, the side displacement is set at $0.1-0.8 \mathrm{~m}$ and the interval is assigned at $0.1 \mathrm{~m}$.

\subsection{Analysis of results}

Under the effects of different landslide displacements, the maximum stress and the maximum strain when the pipeline passes through a catastrophic landslide mass horizontally are shown in Figs. 4 and 5, respectively.

When the landslide area through which the pipeline passes reaches 740-1110 $\mathrm{m}$, the pipeline around it is often severely influenced by the landslide. To analyze the stress and strain conditions near the pipeline in this area in detail, it is required to define a route in the axial direction of the pipeline, and its stress and strain conditions are shown in Figs. 6 and 7.

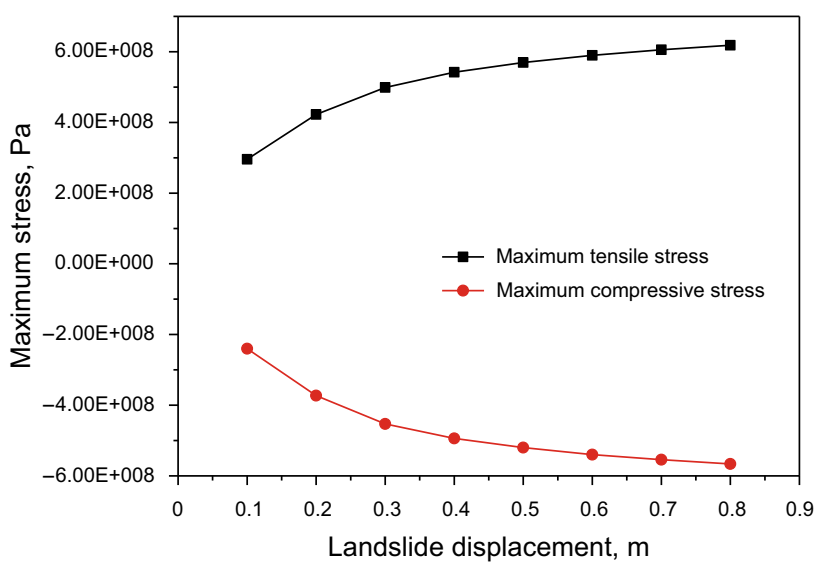

Fig. 4 Maximum stress of a pipeline under the effects of different landslide displacements

It can be observed from Figs. 4 and 5 that when the landslide displacement increases gradually, the maximum stress and strain grows accordingly. When the landslide displacement increases from $0.1 \mathrm{~m}$ to $0.8 \mathrm{~m}$, the tensile stress increases from $312 \mathrm{MPa}$ to $663 \mathrm{MPa}$, the tensile strain increases from $0.14 \%$ to $1.63 \%$, the compressive stress increases from $240 \mathrm{MPa}$ to $566 \mathrm{MPa}$ and the compressive strain increases from $0.13 \%$ to $1.27 \%$.

Under different landslide displacements, the limit values of the axial stress and strain of the pipeline appear at 740

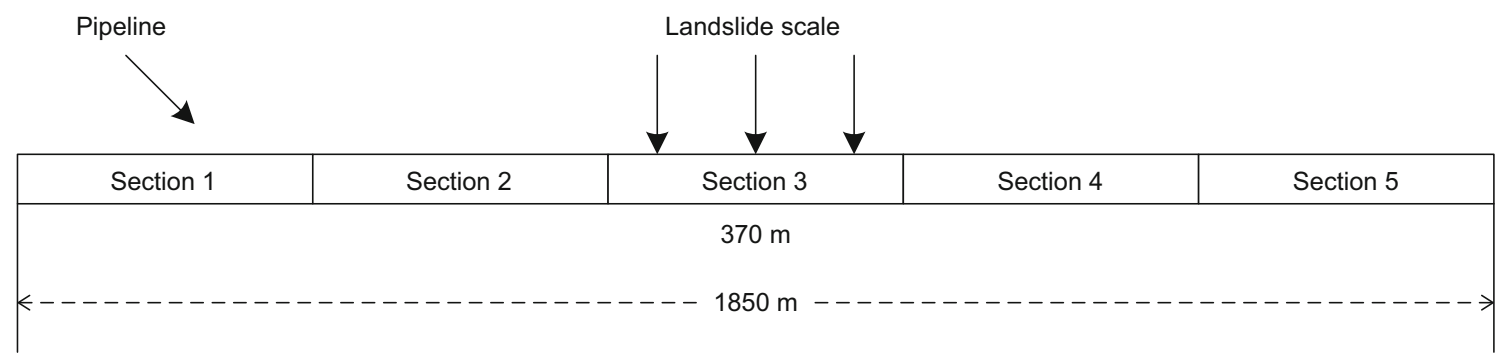

Fig. 3 Schematic diagram of the pipeline model passing through the landslide mass 


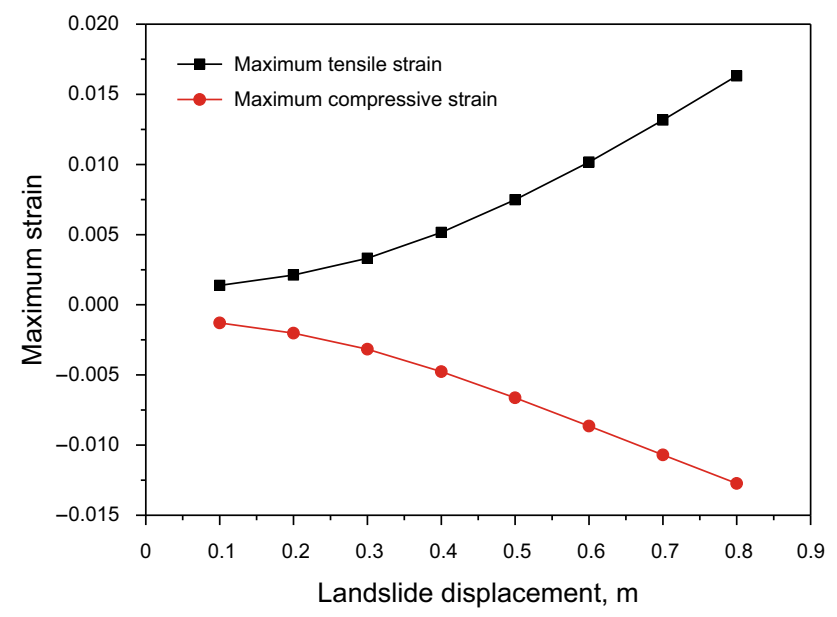

Fig. 5 Maximum strain of a pipeline under the effects of different landslide displacements

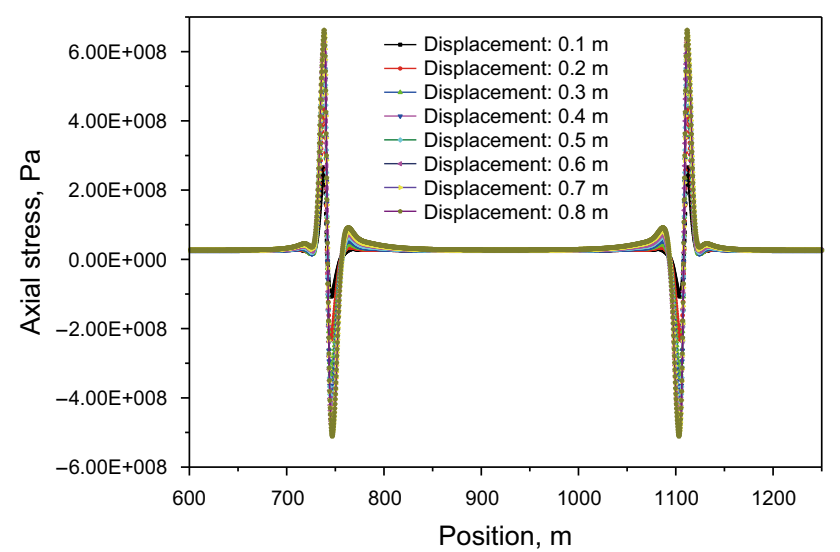

Fig. 6 Axial stress distribution of the pipeline

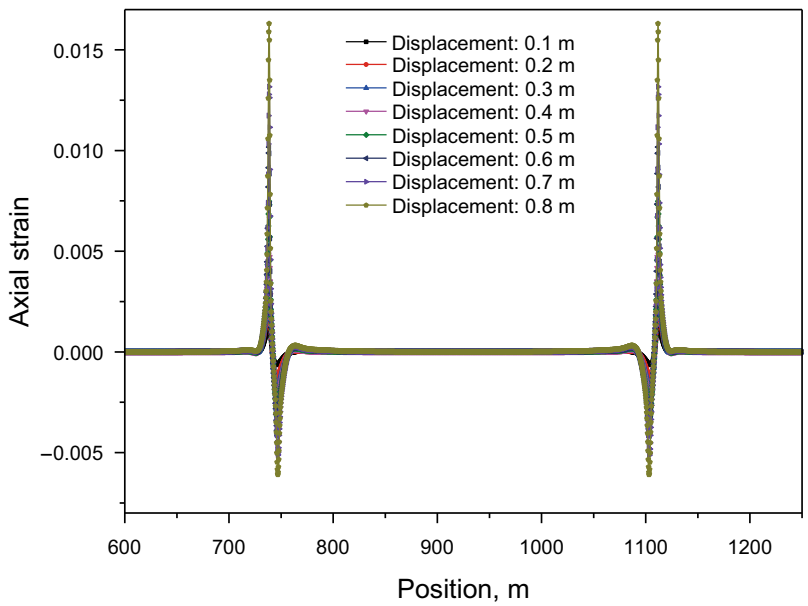

Fig. 7 Axial strain distribution of the pipeline

and $1100 \mathrm{~m}$, which is at the junction of the landslide area and the non-landslide area. In addition, the limit values of stress and strain increase with an increase in the landslide displacement. On both sides of the landslide area, one side

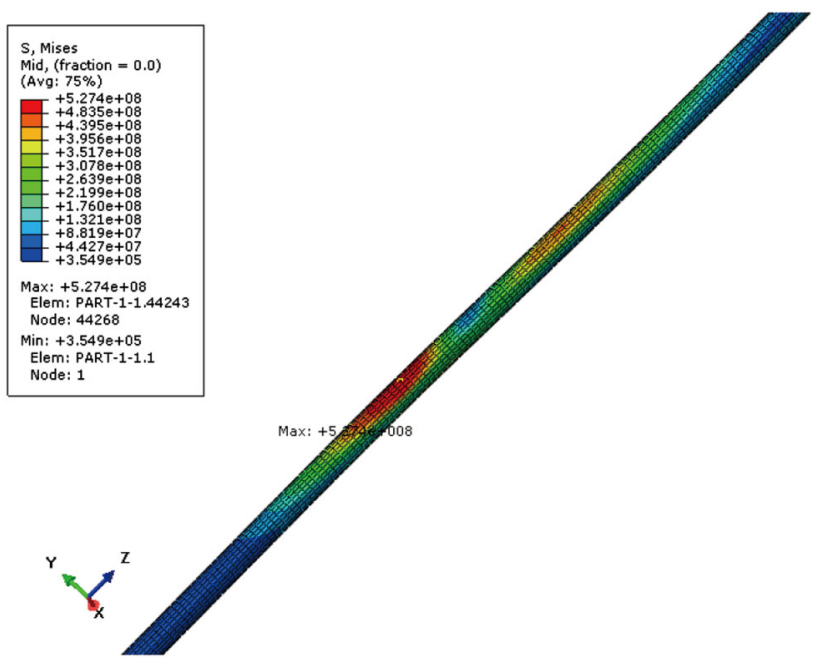

Fig. 8 Stress cloud of a pipeline near the landslide area

of the pipeline is pulled and the other side is stressed. At increasingly longer distances from the interval, the stress values reduce.

When the landslide displacement is $0.3 \mathrm{~m}$, the maximum axial stress on the pipeline is $540 \mathrm{MPa}$. When the landslide displacement is $0.4 \mathrm{~m}$, the maximum axial stress on the pipeline is $584 \mathrm{MPa}$. If the minimum yield strength of the pipe is exceeded, the pipeline is deemed having failed. Upon calculation, the critical value of the landslide displacement causing pipeline fracture is $0.36 \mathrm{~m}$, as shown in Fig. 8.

When the landslide displacement is $0.5 \mathrm{~m}$, the axial tensile strain is $0.75 \%$, and the axial compressive strain is $0.663 \%$. If the axial compressive strain exceeds the allowable compressive strain (allowable compressive strain of X70 pipeline is $0.66 \%$ ), it is deemed that the pipeline suffers from yield damage, as shown in Fig. 9.

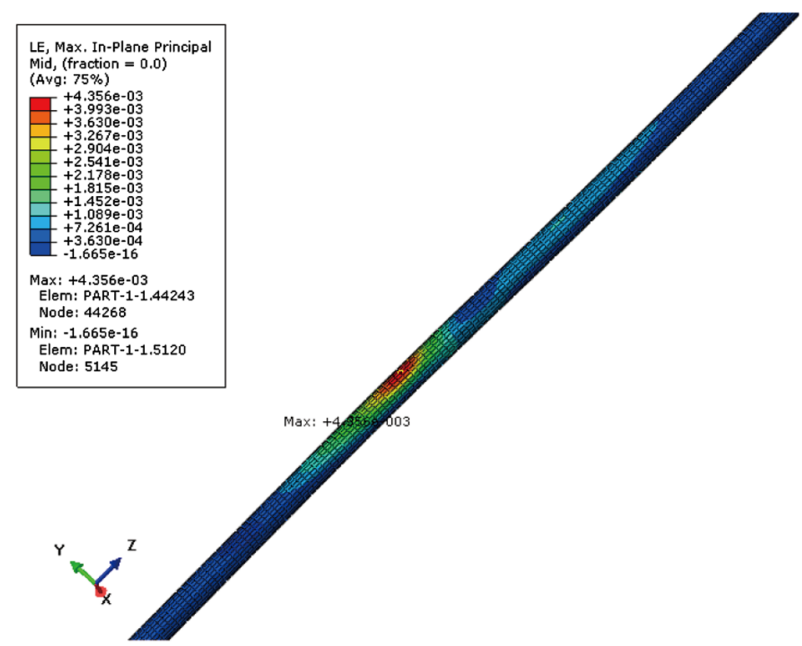

Fig. 9 Strain cloud of a pipeline near the landslide area 


\section{Conclusions}

It can be found from the distributions of axial stress and strain along the pipeline that the limit values of the axial stress and strain appear near the junction of the slide and non-slide areas, which is the dangerous cross section of the pipeline.

The maximum stress and strain increase with an increase in the landslide displacement, and the limit value points are located at the top and bottom of the pipeline. Calibration and verification for strength at this place should be strengthened.

On the basis of the stress failure law, the pipeline fails when the landslide displacement reaches $0.36 \mathrm{~m}$. In accordance with the strain failure law, the maximum strain does not reach the failure threshold in this case, indicating that the stress failure law is more conservative than the strain failure law.

Acknowledgements This research was funded by the National Science and Technology Support Program (2015BAK16B02 and 2015BAK16B01) and the Fundamental Research Funds of China Academy of Safety Science and Technology.

Open Access This article is distributed under the terms of the Creative Commons Attribution 4.0 International License (http://crea tivecommons.org/licenses/by/4.0/), which permits unrestricted use, distribution, and reproduction in any medium, provided you give appropriate credit to the original author(s) and the source, provide a link to the Creative Commons license, and indicate if changes were made.

\section{References}

American Lifelines Alliance (ALA). Guideline for the design of buried steel pipeline. 2001.

Challamel N, Debuhan P. Mixed modelling applied to soil-pipe interaction. Comput Geotech. 2003;30(3):205-16. doi:10.1016/ S0266-352X(03)00011-9.

Deng DM, Zhou XH, Shen YP. Calculation of pipeline inner force and distortion during transverse landslide body. Oil Gas Storage Transp. 1998;17(7):18-22 (in Chinese).

European Gas Pipeline Incident Data Group (EGIG). In: 9th report of the european gas pipeline incident data group (period 1970-2013). 2015.

Hall WJ, Nyman DJ, Johnson ER, et al. Performance of the TransAlaska pipeline in the November 3, 2002 Denali fault earthquake. Long Beach, California. 2003. doi:10.1061/ 40687(2003)54.

Han B, Wang ZY, Zhao HL, et al. Strain-based design for buried pipelines subjected to landslides. Pet Sci. 2012;9(2):236-41. doi:10.1007/s12182-012-0204-y.

Hao JB, Liu JP, Jing HY, et al. A calculation of landslide thrust force to transverse pipeline. Acta Petrolei Sin. 2012;33(6):1093-7 (in Chinese).

Honegger DG, Hart JD, Phillips R, et al. Recent PRCI guidelines for pipelines exposed to landslide and ground subsidence hazards. In: The 8th international pipeline conference, calgary: ASME, 2010. pp. 1-10. doi:10.1115/IPC2010-31311.
Hucka VJ, Blair CK, Kimball EP. Mine subsidence effects on a pressurized natural gas pipeline. Min Eng. 1986;38(10):980-4.

Iimura S. Simplified mechanical model for evaluating stress in pipeline subject to settlement. Constr Build Mater. 2004;18(6):469-79. doi:10.1016/j.conbuildmat.2004.01.002.

Kennedy R, Chow A, Williamson R. Fault movement effects on buried oil pipeline. $\mathrm{J}$ the Transp Eng Division ASCE. 1977;103(5):617-33.

Klar A, Marshall AM. Shell versus beam representation of pipes in the evaluation of tunneling effects on pipelines. Tunnell Undergr Space Technol. 2008;23(4):431-7. doi:10.1016/j.tust.2007.07. 003.

Lin $\mathrm{D}$, Lei $\mathrm{Y}, \mathrm{Xu} \mathrm{KF}$, et al. An experiment on the effect of a transverse landslide on pipelines. Acta Pet Sin. 2011;32(4):728-32 (in Chinese)

Liu H. Response analysis of buried pipeline subject to landslide. Master thesis. Dalian: Dalian university of technology; 2008 (in Chinese).

Liu PF, Zheng JY, Zhang BJ, et al. Failure analysis of natural gas buried X65 steel pipeline under deflection load using finite element method. Mater Des. 2010;31(3):1384-91. doi:10.1016/j. matdes.2009.08.045.

Liu XB, Chen YF, Zhang H, et al. Prediction on the design strain of the X80 steel pipelines across active faults under stress. Natural Gas Ind. 2014;34(12):123-30 (in Chinese).

Liu XJ, Sun SP. Strain design method for underground pipeline crossing fault. Spec Struct. 2005;2:81-5 (in Chinese).

Ma QW, Wang CH, Kong JM. Dynamical mechanisms of effects of landslides on long distance oil and gas pipelines, Wuhan University. J Natural Sci. 2006;11(4):820-4. doi:10.1007/ BF02830170.

O'Rourke MJ, Liu XJ, Flores-Berrones R. Steel pipe wrinkling due to longitudinal permanent ground deformation. J Transp Eng. 1995;121(5):443-51. doi:10.1061/(ASCE)0733-947X.

Rajani BB, Robertson PK, Morgenstern NR. Simplified design methods for pipelines subject to transverse and longitudinal soil movements. Can Geotech J. 1995;32(2):309-23. doi:10.1139/ t95-032.

Shuai J, Wang XL, Zuo SZ. Breakage action and defend measures to pipeline under geological disaster. Weld Pipe Tube. 2008;31(5):9-15 (in Chinese).

Wang LRL, Yeh YH. A refined seismic analysis and design of buried pipeline for fault movement. Earthq Eng Struct Dyn. 1985;13(1):75-96. doi:10.1002/eqe.4290130109.

Wang LW. Study on several typical geological disaster damage assessment methods for in service pipelines. Ph.D. dissertation. Beijing: China University of Science and Technology; 2014.

Wang X, Shuai J, Ye Y, et al. Investigating the effects of mining subsidence on buried pipeline using finite element modeling. In: The 7th international pipeline conference, Calgary: American Society of Mechanical Engineers, 2008. pp. 601-06. doi:10. 1115/IPC2008-64250.

Yan X, Wang T, Yang X, et al. Study on stresses and deformations of suspended pipeline in collapsible loess areas based on elasticplastic foundation model. In: ICPTT 2009, Shanghai: ASCE, 2009:1970-79. doi:10.1061/41073(361)208.

$\mathrm{Yu}$ LQ. Pipeline construction in landslide area. Oil Gas Storage Transp. 1989;8(6):60-4 (in Chinese).

Zhang KY, Wang Y, Ai YB. Analytical solution to interaction between pipelines and soils under arbitrary loads. Chin J Geotech Eng. 2010;32(8):1189-93.

Zhang ZG, Huang MS. Boundary element model for analysis of the mechanical behavior of existing pipelines subjected to tunnelinginduced deformations. Comput Geotech. 2012;46:93-103. doi:10.1016/j.compgeo.2012.06.001. 
Zhao XY, Zhao Y. Strain response analysis of oil and gas pipelines subject to lateral landslide. J Natural Disasters. 2014;23(4):250-6 (in Chinese).

Zheng JY, Zhang BJ, Liu PF, et al. Failure analysis and safety evaluation of buried pipeline due to deflection of landslide process. Eng Fail Anal. 2012;25:156-68. doi:10.1016/j.engfaila nal.2012.05.011.

Zheng W, Zhang H, Liu XB, et al. Application of the strain-based design method in the area of the fault of the Xinyuezhe pipeline. Weld Pipe Tube. 2015;38(4):38-42 (in Chinese). 